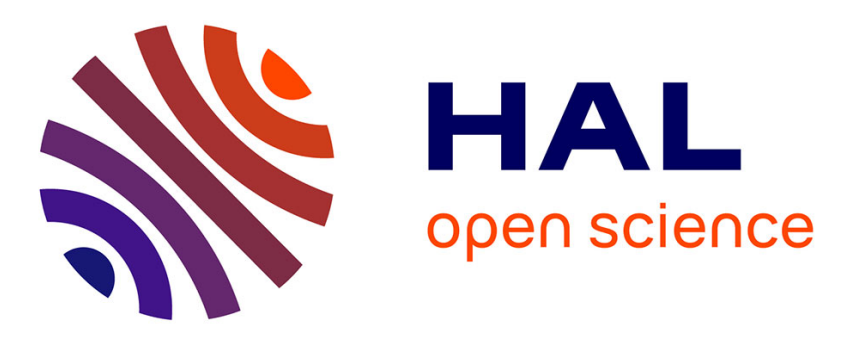

\title{
Functions of mental imagery in expert golfers
}

\author{
Marjorie Bernier, Jean F. Fournier
}

\section{To cite this version:}

Marjorie Bernier, Jean F. Fournier. Functions of mental imagery in expert golfers. Psychology of Sport and Exercise, 2010, 11 (6), pp.444 - 452. 10.1016/j.psychsport.2010.05.006) . hal-01753418

\section{HAL Id: hal-01753418 https://hal-insep.archives-ouvertes.fr/hal-01753418}

Submitted on 29 Mar 2018

HAL is a multi-disciplinary open access archive for the deposit and dissemination of scientific research documents, whether they are published or not. The documents may come from teaching and research institutions in France or abroad, or from public or private research centers.
L'archive ouverte pluridisciplinaire HAL, est destinée au dépôt et à la diffusion de documents scientifiques de niveau recherche, publiés ou non, émanant des établissements d'enseignement et de recherche français ou étrangers, des laboratoires publics ou privés. 


\title{
Functions of mental imagery in expert golfers
}

\author{
Marjorie Bernier ; Jean F. Fournier \\ Institut National du Sport, de l'Expertise et de la Performance, Recherche, 11 avenue du Tremblay 75012 Paris, \\ France
}

Article publié dans : Psychology of sport and exercise (ISSN 1469-0292), 2010, vol. 11, n 6, pp. $444-452$ (DOI : 10.1016/j.psychsport.2010.05.006)

\begin{abstract}
Objectives: This two-study article examines the functional aspects of the use of imagery and describes the relationship among function, content and characteristics of mental images used by expert golfers in different situations.

Method: In Study 1, three methods of interviews (field interviews self-confrontation interviews and focus group) were used with 21 expert golfers to collect data about their use of imagery. In Study 2, 31 expert golfers were exposed to different situations (task-involving vs. ego-involving situations, easy vs. difficult tasks conditions) in order to examine the links between: (a) the function and the content, and the function and the characteristics of their mental images, and (b) the situation and the function of their mental images.

Results: Results indicated that one category of content (images of the outcome with an internal perspective) was principally used by all participants. Moreover, the expert golfers adapted the content and the characteristics of their images according to the function that was required by the situation. The influence of the situation on imagery use highlighted in Study 1 was not confirmed in Study 2.

Conclusions: Results confirm the links among function, content and characteristics of imagery postulated recently (Fournier, Deremaux, \& Bernier, 2008; Murphy, Nordin, \& Cumming, 2008; Nordin \& Cumming, 2005). Taking into consideration these functional links should enhance the relevance of future research and help the sport psychology practitioner to better understand athletes' use of imagery. The influence of the situation on imagery use still requires further exploration.
\end{abstract}

Hardy and Jones (1994, p. 67) define mental imagery as "a symbolic sensory experience that may occur in any sensory mode." Imagery may influence physical performance (Driskell, Copper, \& Moran, 1994; Murphy, Nordin, \& Cumming, 2008), and is thus a major research theme. The understanding of the relationship between mental imagery and sport performance has progressed along two different fines of research that seek to optimise the use of imagery by athletes. The first line studies the functional equivalence between real and imagined movement. Functional equivalence is related to the simulation theory (Jeannerod, 2001) that postulates that covert or imagined actions are considered as actions not actually executed. The second line of research, with which this article deals, regards the applied use of imagery by athletes. Several models have been presented to explain how athletes use mental imagery. The model proposed by Martin, Moritz, and Hall (1999) has been used in various studies to explore and improve understanding of the use of imagery by athletes. Martin et al.'s model supplements Hall, Mack, Paivio, and Hausenblas' (1998) original model, itself based on Paivio's (1985) functions model. Martin et al.'s model is made up of three main components: situation, type and outcome. This model postulates that athletes' mental imagery sessions take place in three different situations: training, competition and rehabilitation. Second, five imagery types include: (a) Cognitive Specific, (b) Cognitive General, (c) Motivational General-Mastery, (d) Motivational General-Arousal and (e) Motivational Specific. These types are also called the function or the purpose that the imagery is serving. The third component encompasses three outcomes that athletes hope to achieve: (a) to learn skills and strategies for performance, (b) to modify cognitions, (c) to regulate arousal and competitive anxiety. Hall et al. (1998) developed a questionnaire based on Paivio's (1985) functions model: the Sport Imagery Questionnaire (SIQ). The SIQ appraises the extent to which the five imagery types are used.

Martin et al.'s (1999) applied model and the SIQ have been used in numerous studies (e.g., Cumming, Clark, Ste-Marie, McCullagh, \& Hall, 2005; Gregg, Hall, \& Nederhof, 2005; Short et al., 2002). Recently, some limitations of the assessment tool and of the model have been highlighted due to the confusion between imagery type, function and outcome. Researchers have noted that a participant may use the same image for different reasons (Calmels, 
D'Arripe-Longueville, Fournier, \& Soulard, 2003; Fournier, Deremaux, \& Bernier, 2008; Hare, Evans, \& Callow, 2008; Murphy et al., 2008; Nordin \& Cumming, 2005; Short, Monsma, \& Short, 2004) rather than equating content with function. The confusion between content and function of imagery is also present in the SIQ. Short et al. (2004) pointed out that previous studies have made the mistake of selecting one function for each image.

In two more recent model propositions (Fournier et al., 2008; Murphy et al., 2008), three key concepts emerged: content (or type), characteristics and function. These three concepts are defined and integrated in more complex models by the authors to explain how athletes use imagery. Their definitions of the three concepts are similar, which suggests that these terms are relevant. The content (or the type) of a mental image is what is imagined. The content may include various elements (e.g., the movement itself, the outcome, the environment). It is not limited to the types defined in Martin et al.'s model (i.e., CS, CG, MS, MG-A and MG-M) that, for the reasons previously outlined, does not distinguish between content and function. Fournier et al. (2008), Nordin and Cumming (2005) and Murphy et al. (2008) have suggested newly identified kinds of content according to the sport in which they studied imagery use (e.g., images depicting emotions, images of the context, images of strategy, body-related images). Fournier et al. (2008) suggested that the content of a mental image is defined both by a focus of attention (i.e., what is seen in the image) and by the perspective (internal vs. external). In a view different from Munroe, Giacobbi, Hall, and Weinberg's (2000) framework, which considered perspective as a characteristic of mental imagery, Fournier et al. (2008) argued that what is seen is determined by the perspective. Thus the perspective is an element of the content. Characteristics are how mental images are imagined. Murphy et al. (2008) integrated various characteristics in their neurocognitive model of imagery: imagery amount, duration, direction, deliberation and modality. Other characteristics emerged from imagery uses of elite skydivers in the Fournier et al. (2008) study; they were speed, vividness and colour. Finally, the function corresponds to the reason why mental images are imagined. For example, one may use mental images in order to learn or to get motivated. Functions are linked to the rote attributed to mental images, or to the goal sought through the use of mental images. In both recent models the concept of function is central. "Thus the column labeled imagery function is in some ways the most important part of the model, because the choice of goals will highly influence the nature and process of the ensuing cognitive activities." (Murphy et al., 2008, p. 309).

Fournier et al. (2008) and Murphy et al. (2008) used the same three key concepts in distinct approaches. Murphy et al. (2008; considered these three components in a neurocognitive approach establishing links between cognitive processes. This model also draws attention to the imagery "outcome" or the behavioural, affective and cognitive effects of imagery. Fournier et al.'s (2008) model is based on a dynamic approach highlighted in two studies with skydivers that contends that the three elements (content, characteristics and function) vary with the demands of the situation. Thus the model points out that the situation influences imagery use, The content and the characteristics of mental images are generated because they correspond to specific needs, or functions, in specific situations (e.g., easy or difficult sequences, in different steps of the preparation for the jumps). Nordin and Cumming (2005) also observed differences in imagery content depending on the time (e.g., times of day, practice, performance, certain periods of the year). It is therefore necessary to consider and define the notion of "situation". Indeed, many elements (e.g., time, context, specificity of the task) that can be classified as situation seem to have an influence on imagery use. Hence, situation is understood in the present article as "a combination of all the things that are happening and all the conditions that exist at a particular time in a particular place" (Pearson Longman. 2009).

Since the concept clarifications are recent, the present study aimed to replicate and extend previous findings on the three key concepts. The first qualitative descriptive study was designed to explore imagery function, content and characteristics with a sample of elite athletes in the sport of golf. The second goal of Study 1 was to explore more thoroughly the functional links between the concepts suggested by recent studies. The influence of the situation mentioned by Fournier et al. (2008) and Nordin and Cumming (2005) was also examined in this exploratory study. In addition, a quantitative quasi-experimental research study (Study 2) was performed with elite golfers to confirm some specific links that seemed central in imagery use: (a) the link between function and content, and function and characteristics, (b) the link between situation and function. The goal was to deepen our knowledge about the relationships among the concepts. 


\section{Study 1}

The goal of this first qualitative study was to describe mental imagery used by expert golfers regarding its content (what does an expert golfer imagine in preparing the shot?), its characteristics (how does the golfer imagine it?), its functions (why does the golfer use these images?) and the links between these three elements. The study also explored the influence of the situation on imagery use. The study was based on a design with three qualitative methods in order to optimise data collection. As this study was exploratory, researchers took into account the images used by golfers in ecologically valid conditions.

\section{Method}

\section{Participants}

Twenty-one expert golfers ( 6 female and 15 male: $\mathrm{M}$ age $=26.36, S D=4.68$ ) volunteered to take part in this research study. The participants had practised golf for $12-25$ years $(\mathrm{M}=16.31, S D=3.38)$. According to criteria defined by Ericsson, Krampe, and Tesch-Rômer (1993) they were thus considered expert athletes. Nine players were elite amateur golfers and had a handicap between -2 and 6 . Three of them participated in international amateur tournaments (European and World Championships). The other twelve participants were professional golfers and had competed in various professional tours (Alps Tour, Challenge Tour, European Tour). Because they were professionals, they did not have official handicaps but their play level corresponded to a negative handicap. All players signed an informed consent form and were told that they could withdraw at any time from the study.

\section{Design}

To increase validity, the same phenomena were observed with three different qualitative methods (field interview, self-confrontation interview and focus group), the strengths of one offsetting the weaknesses of the others. Golfers were assigned to each method according to their availability when one method was used. Professional and amateur golfers ended up being distributed equally in each method.

Field interviews were held during play with 7 players ( 2 professional female, 3 amateur male and 2 professional male). A researcher accompanied each golfer as they played a 9-hole course. After each shot he/she asked the golfer a series of questions to describe the mental images used both before and after playing each shot. The interviews were audio recorded to allow for later transcription. This method allowed for stimulating immediate recall of the images used in the previous situation. However, the interview process between two shots might have an influence on the following imagery experiences on the course.

Self-confrontation interviews (von Cranach \& Harré, 1982) were held with 6 players (2 professional female, 2 amateur male and 2 professional male). Players were filmed during a 9-hole round of play. They were followed by the researcher for the duration of the round. Individual interviews were held one hour after the end of the game. The video that was taken was presented to the player and he/she was asked to describe the mental images that he or she used before each shot. A video recorder was used to record each interview. Based on the techniques of stimulated recall (Trudel, Haughian, \& Gilbert, 1996), this interview method fostered the recall of imagery experiences by means of the video.

A focus group was established with a group of 8 players ( 2 professional female, 4 amateur male and 2 professional male). The researchers followed standard focus group guidelines described by Morgan and Krueger (1998). A group leader (the first researcher) conducted the focus group interviews with the help of a technical assistant (the second researcher), who took field notes. Following the procedure described by Morgan and Krueger, the group leader asked the players to describe and discuss their experiences using mental imagery. A video recorder was used for transcription of the interview. In the focus group the golfers did not comment on specific situations and specific imagery experiences, as in the two other methods. Sharing experiences with a collective interview provided additional data dealing with general and everyday imagery use.

\section{Interview guide}

All interviews were semi-structured in nature. The following themes were addressed during the 
interviews: (a) description of the situation in which mental imagery was used (e.g., type of shot, difficulty, environment); (b) description of the content of the mental images (What did you imagine?): imagery perspective, focus of attention in the mental imagery (swing, club, trajectory, target, environment); (c) description of the imagery characteristics (How did you imagine?): vividness, speed, colour; (d) function of the images (Why did you use these images?). The full interview guide, with the probes, is available upon request from the authors.

\section{Validity, trustworthiness}

The results of the present research can be considered trustworthy because they meet Sparkes's (1998) criteria in the design, data collection and analysis. Credibility (member checks, prolonged engagement, triangulation), transferability (thick description) and confirmability (inquiry audit) were addressed (Sparkes, 1998). The two interviewers and analysts were sport psychology researchers. The first author had been studying imagery for the last four years and was trained in qualitative research. The second author had been using qualitative analysis and had studied imagery for over 10 years. He had been teaching psychological skills training to elite amateur golfers for 5 years. His knowledge of expert golfers and his involvement with them established his credibility because of prolonged commitment to, and long-term observation of, the players. The two analysts independently completed the inductive coding of the transcripts. A psychology researcher from a different institution performed an independent audit. She had no experience of research in mental imagery or in the sport of golf. She was trained in qualitative methods and unaffiliated with this study. This independent audit provided a means of cross-validation and ensured that the authors' categorizations were reliable.

\section{Data analysis}

Analysis of the data was processed in three stages. In the first stage, we processed a coding of the meaning units (MUs). This stage allowed us to select MUs with regard to what participants said they were doing. In the second stage, tags with similar meaning were gathered within the same category or sub-category. During the third stage, we tried to appraise relationships among the categories and sub-categories. During the whole data analysis, both deductive and inductive reasoning were used (Patton, 2002). Since the interview guide was based on recent findings (Fournier et al., 2008; Nordin \& Cumming, 2005) its use was imbedded in a deductive analytical procedure. Additional categories and links that emerged out of the analysis resulted from an inductive approach to understanding the data. Inter-observer agreement on the codes (Thomas \& Nelson, 1996) reached 91\%. Moreover, the external audit was performed on a sample of interview excerpts. The sample included interview excerpts obtained with the three methods: (a) 37 excerpts taken from 4 field interviews, representing $1 \mathrm{~h} 35$ out of $6 \mathrm{~h} 17$ (total of all interviews), or $25 \%$; (b) 26 excerpts taken from 5 self-confrontation interviews, representing $2 \mathrm{~h} 27$ out of $7 \mathrm{~h} 54$ total, or $31 \%$; (c) the full video recording of the focus group. Excerpts with the richest content were selected to make up the sample, that is to say, excerpts with a maximum of MUs related to the golfers' imagery use. When this audit was included in the sample, inter-observer agreement among the three researchers reached $88 \%$.

\section{Results}

Fig. 1 presents the emergent categories of: (a) situations in which mental imagery is used, (b) image function, (c) image content (focus of attention and perspective) and, (d) image characteristics (speed, colour, vividness). Other results dealing with the main imagery content and the links among situation, function, content and characteristics are reported in the results section. Visual imagery was emphasised because the use of auditory and kinaesthetic imagery was rare. Moreover the interview guide may not have accommodated well the investigation of the use of non-visual imagery.

\section{Main imagery content}

Content is characterised by: (a) the focus of attention in the imagery, and by (b) perspective (internal, external or both). The main imagery content used by these expert players concerned the trajectory (the flight) of the ball in the air, or the roll of the ball on the ground, as seen from an internal perspective. According to the players, this content was helpful because it gave information relevant to the execution of the swing. Imagery of a trajectory of the ball (or a roll of the ball) took various forms. Some players imagined a transparent ball travelling on a background picture of 
the course; other players imagined a line (usually black, but sometimes white or of other colours) drawn across this background picture:

(I visualise) the flight of the ball. The ball is already up in the air, after the swing. I don't see the end of the trajectory, and the ball doesn't land. It's like a line, like the white smoke behind a jet plane. The line is drawn as the ball flies, and blurs afterwards. (Player M)

Only a few golfers reported that they used other focus of attention in their imagery during a round, such as images of the swing. Mental images were also related to contextual elements (e.g., the environment, obstacles, slopes) or events not linked at all to the context (e.g., images of life outside of golf).

Players seemed mostly to use an internal perspective because it brought specific information and helped them to perform. Sometimes, external perspective was used in cases where additional information about the environment was needed:

Sometimes, when I walk, I try to use the external view. I walk and I see myself play (...) when I'm behind the ball, I use the internal view: very often, I see myself hit the ball internally; I see the swing, and the club moving. I make my practice shot in my head. And when I see the ball fly, I see its trajectory. (Player E)

\section{Links among situation, function, content and characteristics: towards a functional use of mental imagery Links between situation and function.}

A player placed in a specific situation used imagery for a specific reason. Hence situation and function were linked. Imagery functions were related to a given situation: e.g., the type of shot (driving or putting), the environment (the wind, the lie of the ball), the difficulty of the shot, or the level of a player's confidence. Each use of imagery corresponded to the situation. For example, Player $\mathrm{M}$ explained that depending on the type of shot, he did not necessarily use imagery for the same function:

For the long shots in a game, I visualise in order to focus on the trajectory of the ball, and (I) forget about the swing; but for the short shots, I use imagery to be more precise and to enhance my confidence.

Similarly, he used imagery before and after training sessions, but for different functions. Mental images were used to "prepare training session" the morning before playing, whereas they were used to "consolidate work done during training" in the evening.

Links between situation and content. Imagery content depended on the situation in which the golfer was placed. Thus, the type of shot influenced the content of mental images created before play. For example, the trajectory or the roll of the ball imagined was different according to the type of shot. Some players mentioned that, before a short shot requiring precision, they would use more mental imagery. The same level of precision (regarding the imagery of the trajectory or the roll of the ball) was used when the ball was lying close to the hole:

The closer I get to the hole, the more I visualise the full trajectory. (Player B).

The closer I am to the hole, the more I imagine the end of the trajectory. (...) Each hole is different; hence what I imagine is different. (Player A)

In a given pre-shot routine, mental imagery was used several times. Different kinds of imagery content were generated at each step of the pre-shot routines. Player $M$ described two different kinds of imagery content inside his pre-putt routine:

When I look at the line-up, I try to see how the ball will roll, to imagine the roll that the ball will Lake. (...) And then, when I address the ball, I imagine the ball falling into the hole.

Moreover the imagery content depended on the golf training period of the preparation of a tournament or a competitive season:

The deeper we get into the season, the more shots I imagine. I use much more imagery of shots. (Player F).

Links between function and content. Each player adapted the content of his or her mental images according to the goal sought when using mental imagery. Hence there was a link between what was seen (content) and why it was seen (function). The following player explained that she manipulated 
her mental images to prepare the technical aspect of the shot before playing. Thus the content varied according to the goal she set:

The ball should go over the hole and $30 \mathrm{~cm}$ beyond. This helps me be more aggressive. (...)

I aim for the top of the flagpole. I exaggerate the trajectory to better control it...I want to control what I want to do. So I visualise the control of the ball with amplified types of trajectory. (Player D).

We noted that one main function of mental imagery used by golfers was to "get focused". Adaptation of the image content enabled them to modify the focus of attention in order to achieve optimal concentration with regard to the shot to be played. The function of activation management (to relax or to get more excited) was obtained by imagery content related to trajectory or roll. Players highlighted rhythm or speed in the description of imagery content. This function was sometimes linked to metaphorical content. In the latter case, the image evoked elements more or less related to golf but that symbolised either cairn or arousal:

Because I know that I'm a bit anxious, I see a duck in the water. This relaxes me when I feel that I'm getting nervous for a shot. (Player D).

Functions linked to strategic preparation of a shot on the course also corresponded to relevant content that brought the information needed to make the proper tactical choice. When a player had a choice to make among various trajectory options, the link between the strategic function and the content of mental images was very important. Golfers had learned to use imagery content to enable them to collect information, to analyse the different trajectory options and to choose the more efficient one, or the trajectory that gave them more confidence in the execution of the shot. Hence player $\mathrm{N}$ reported using imagery twice during the preparation of a chip, when the function of mental imagery was to choose a shot from different options. The first time, he visualised with an external perspective the different possible trajectories of the ball in order to project the outcome (where the ball will land, and how it will roll). The second time, just before playing, he visualised with an internal perspective the chosen trajectory to validate the decision of the chosen shot.

Evaluation functions (to correct a swing, to evaluate oneself...) related to specific content. For example, the following player used imagery after a poorly executed shot in order to visualise the trajectory that he should have produced:

In that case, I visualised the trajectory that I was trying to make because I produced a poor shot... So I imagined the shot again, visualised the trajectory... where the ball landed, what I really wanted to do: the shot I wanted to come up with. (Player G).

Adapted characteristics of mental images. By modifying the characteristics of their mental images, golfers optimised their use of imagery because adapted images helped them select more relevant information. To do so, some players modified the speed of their mental pictures:

I try to visualise the speed of the ball, how it will roll on the grass, when it will accelerate (...) Speed tells me what the slope is like; it gives me all the information. So I see with the real speed; it tells me how I want it to behave. (Player G).

Players could also modify the speed of images during visualisation:

In my imagery, my ball takes off very quickly and, at the end, I see how it falls, at a slower speed than in reality. (Player A).

Vividness of mental images seemed to be infiuenced by the difficulty of the shot and by the level of confidence of the player. One player explained that her mental images were not clear when she was lacking in confidence.

Here the putt is easy. I can visualise the line very clearly. I can almost see the ball that follows the path. For the putt of the 6 , it was different. I was not confident. I imagine a blurry and thick line. (Player D).

Characteristics of mental images were therefore dependent upon the other elements described above. Indeed, images varied depending on the situation of the player, and on the function of the 
mental images.

This first study was helpful in identifying categories of content, characteristics, situation and function (see Fig. 1). Links among elements (situation, function, content and characteristics) highlighted recently (Fournier et al, 2008; Murphy et al., 2008; Nordin \& Cumming, 2005) were found in the experiences related by expert golfers. The functional aspect of the use of imagery seems as prevalent in golf as it was in skydiving (Fournier et al., 2008) and dancing (Nordin \& Cumming, 2005). To better understand the functional aspect of the use of imagery, a second, quasi-experimental study was deemed necessary.

\section{Study 2}

Results of Study 1 provided descriptive findings. Therefore there was a need to validate this approach of imagery use by way of a confirmatory study. Hence, the goal of the second study was to confirm this approach by especially examining two links that seemed central in previous findings. First, it seemed relevant to test the links among function, content, and characteristics described in Study 1. The second link tested in Study 2 was the link that emerged in Study 1 and in Fournier et al. (2008) between situation and function. It was necessary to confirm the influence of the situation in which the golfer finds himself or herself on the image function. To create different situations, we chose to manipulate both the motivational situation (task-involving situation vs. egoinvolving situation) and the difficulty of the task (an easy shot vs. a difficult shot). By manipulating these $2 \times 2$ situations the goal was to test the following two hypotheses: (a) the imagery function is linked to content and characteristics, and (b) the situation (in this study, the motivational situation and the task difficulty) influences the imagery function.

\section{Method}

\section{Participants}

Thirty-one amateur golfers ( 28 men and 3 women; $\mathrm{M}$ age $=25.61, S D=428$ ) volunteered to participate in the present study. They had practised golf for $11-23$ years $(\mathrm{M}=16.14, S D=332)$. According to Ericsson et al. (1993) they were considered expert athletes. Their golf handicaps were between -2 and +6 . Two groups of similar level were created. Group $1(\mathrm{n}=16)$ was exposed to an ego-involving situation white Group $2(\mathrm{n}=15)$ was immersed in a task-involving situation. Players were divided into the two groups based on performance and imagery skill criteria. They were first ranked based on their most recent official handicap. However, they complained that the handicap was not a gond indicator of their current level of play and they took it upon themselves to modify the first ranking based on the most recent competitive results. All the participants validated the ranking. Then, their imagery skills were appraised with the VMIQ (Vividness of Movement Imagery Questionnaire; Isaac, Marks, \& Russell, 1986), both translated into and validated in French by Fournier, LeCren, and Monnier (1994). This questionnaire evaluates the sharpness of mental images with the Likert scale ranging from 1 (no image at all) to 5 (images as clear as in real life). Four players who did not score over 72 were considered poorly skilled (Hardy \& Callow, 1999). The latter were split up and assigned to either group. All players signed an informed consent foret and were told that they could withdraw at any time.

\section{Task}

The task consisted of a series of 10 chips around the putting green. A numbered plastic cone around which players had to place the ball indicated each shot. Each cone was located $15 \mathrm{~m}$ away from the hole indicated by a flag with the number of the cone. All even chips were considered easy (technically simple) and every uneven shot was more difficult (lob shot, or stepped slope, or with an obstacle between the cone and the hole). The difficulty of the task (easy or difficult) was used to confront the players with two different situations, where difficulty of the task functioned as a variable. Golfers were instructed: (a) to hole the ball or get it as close as possible in a single shot, and (b) to use mental images before the shot. The latter instruction was supposed to encourage the participants to choose the content, characteristics and function of their mental images. After the shot, performance was appraised by the distance between where the ball landed and the hole. 


\section{Motivational situation manipulation}

From motivation theories and in particular from achievement goal theory (Ames, 1992; Nicholls, 1989), two motivational situations were created.

Ego-involving situation. Players from this group were invited to take part in a competition, one on one, two people going around the course together. Each of them agreed to bet five euros. The winner got $40 €$, the second $24 €$, and the third $16 €$. Betting money in a golf round is common practice between players to increase the pressure. All amounts were given back to the players at the end of the experiment.

Task-involving situation. Players from this group were asked to train atone white playing the 10 chips. The task was presented as on opportunity to enhance their chipping technique.

\section{Assessment tool}

Players were given a leaflet with a set of questions to be answered after each shot. Questions were pilot tested with three expert golfers practicing on the driving range. A golf instructor checked the relevance of the golf-related vocabulary. Since directed interviews were time consuming for 31 golfers, we modified the questions to fit an 11-paged leaflet format. The first page presented the study, imagery and the questionnaire itself. The remaining 10 pages contained a list of seven questions that players answered after each shot. Questions were related to performance (distance from ball to hole) and to content (focus of attention and perspective), characteristics (vividness, speed and colour) and function of images used before the shot. Only the content, characteristics and function related answers were used in this study.

\section{Results}

\section{Data analysis}

For each shot, the questionnaire made it possible to collect the following qualitative data: (a) the situation defined by the motivational situation (task-involving vs. ego-involving situation) and the task difficulty (easy vs. difficult shot), (b) the content defined by the focus of attention in the imagery and the perspective, (c) the characteristics defined by the vividness, speed and colour, and (d) the function. Data were analysed by taking into account each shot as a statistical unit. A table composed of 310 lines corresponding to each shot and 31 columns corresponding to the answers to the leaflet questions was analysed. Some answers were coded inductively. Categories close to those identified in Study 1 were found. For the question "describe as precisely as possible what you have imagined", answers were coded into four categories of "focus", defined as the focus of attention in the mental imagery: (a) images of the process: partial or total images of the swing; (b) images of the outcome: mental images of a part or all of the trajectory or the roll of the ball, ball in the hole, or images of success; (c) images associating both process and outcome; (d) no image: the player did not imagine or did not manage to create mental images before playing. Functions were classified into 6 categories. Functions related to: (a) learning and perfecting one's swing (making a good swing, correcting one's swing, enhancing one's swing), (b) focusing, (c) excelling (to beat other players, to enhance the outcome), (d) gaining confidence, (e) managing stress and arousal (to manage stress, to be more excited, to be more relaxed), (f) getting motivated. Other imagery modalities (auditory or kinaesthetic) were seldom used by the participants. Data on these modalities were so scarce that a statistical analysis was not relevant.

A chi-square test was processed to examine links among various qualitative variables: motivational situation, task difficulty, function, perspective, focus, speed, vividness, and colour. A significant global chi-square indicates a link between two qualitative variables. When the chi-square was significant, a chi-square per cell (Grimmer, 2004) was calculated to detect links between two levels (or categories) of two given qualitative variables. Each of the cells of the contingency table between two variables was studied. Then this allowed for testing the link between two levels (or categories), in a four-cell contingency table (Cibois, 1993, 2009). To test the relationship between function and content and function and characteristics, we computed 5 chi-squares and 90 chi-squares per cell: (a) function and perspective, followed by 18 chi-squares per cell; (b) function and focus, followed by 24 chi-squares per cell; (c) function and speed, followed by 18 chi-squares per cell; (d) function and vividness, followed by 18 chi-squares per cell; (e) function and colour, followed by 12 
chi-squares per cell. To test the relationship between situation and function, we computed 2 chisquares and 24 chi-squares per cell: (a) motivational situation and function, followed by 12 chisquares per cell; (b) difficulty and function, followed by 12 chi-squares per cell.

A validity check showed that there was no significant difference in chipping performance between the two groups, $\mathrm{t}(22)=-1.31, \mathrm{p}=.20, d=0.52$. A t test demonstrated that the easy and difficult task did lead to different performance, «307) $9.05, p<.01, d=1.03$. The average performance on the easy shot is significantly shorter (hence better) than the performance on the more difficult shots.

\section{Links between content and function}

Chi-square indicates that functions and perspectives are linked, $\mathrm{x}^{2}(10.275)=32.91, p<.001$. A similar result was observed for the functions and focus of attention, $\mathrm{x}^{2}(15,289)=72.24, p<.01$. Therefore we examined the relationships: (a) between the categories of perspective and the categories of function and, (b) between the categories of focus of attention and the categories of function. Chi-squares per cell indicate an overrepresentation of the external perspective for the "to perform" function, $\mathrm{x}^{2}$ per cell $(10,275)=3.10, p<.05$, and for the "to manage stress and arousal" function, $\mathrm{x}^{2}$ per cell $(10,275)=11.41, p<.05$ (for the percentages, see Table 1). Chi-squares per cell indicate an overrepresentation of images of the process for the "to learn and perfect one's swing" function, $)\left({ }^{2}\right.$ per cell $(15,289)=430, p<.05$, and an overrepresentation of images associating both process and outcome for the "to gain confidence" function, $\mathrm{x}^{2}$ per cell $(15,289)=13.02, p<.01$ (for the percentages, see Table 1).

Whatever the function, the image content used most is of outcome from an internal perspective. Images of the outcome are used in 53\% of the 310 shots (or imagery experiences) and internal perspective is used in 55\% of the shots (see Table 1).

\section{Links among characteristics and function}

The three characteristics are significantly linked to image function: speed, $\mathrm{x}^{2}(10,265)=33.48, \boldsymbol{p}<.01$; colour, $\mathrm{X}^{2}\left(5,2^{4} 3\right)=-1829, p<.05$ and vividness, $\mathrm{x}^{2}(10,282)=23.16, p<.01$. Characteristics are used differently depending on the function of the images (for the percentages, see Table 2).

Among the significant resuits in chi-squares per cell testing the speed-function link, we observed an overrepresentation of slower than real time images for the "to focus" function, $) \mathrm{C}^{2}$ per cell $(10,265)=5.08, p$ $<.01$, an overrepresentation of the real speed images for the "to gain confidence" function, $)\left({ }^{2}\right.$ per cell (10, $265)=3.58, p<.01$ and an overrepresentation of faster than real time images for the "to get motivated" function, $x^{2}$ per cell $(10,265)-9.06, p<.01$. In the vividness-function link, we noted an overrepresentation of very blurry images for the "to manage stress and arousal" function, $\mathrm{x}^{2}$ per cell $(10,282)=9.85, p$ $<.01$. In the colour-function link, an overrepresentation of black and white images for the "to manage stress and arousal" function emerged, $\mathrm{x}^{2}$ per cell $(5,243)=9.69, p<.01$.

\section{Links between function and situation (motivational situation and task difficulty)}

Chi-square tests between function and motivational situation variables, $\mathrm{x}^{2}(5,284)=5.21, p .39$, and between function and task difficulty were processed, $\mathrm{x}^{2}(5,284)=3.51, p .62$. Results were not significant. Hence links between the situations created (task-vs. ego-involving situations and easy vs. difficult tasks) and the function related to imagery were not detected.

\section{Discussion}

\section{Links among functions, content and characteristics of mental images}

The goal of these studies was to examine imagery use in expert golfers. Results of the present two studies enhance our knowledge about the three imagery elements revealed in recent studies (Fournier et al., 2008; Murphy et al., 2008; Nordin \& Cumming, 2005). In both studies the coding process provided new categories of function, content and characteristics. Some aspects of this classification resemble the ones presented in Nordin and Cumming (2005) and in Murphy et al. (2008). Some imagery function categories described in the latter were found in the present study. They are related to motor control and the planning of technical aspects (e.g., to learn, to plan, to correct, to repeat, to memorise a movement), related to problem solving or decision-making (e.g., to gather relevant information, to choose one's strategy) and even related to confidence and arousal management (e.g., to gain confidence, to psych up, to calm down). However, the classifications are different for other dimensions. Differences are mostly due to the specificities of the sport. For example, in Nordin and Cumming (2005), some categories of content that dancers made reference to were related to the artistic component of this sport. They are 
different from the categories of content in golfers, for whom content is more related to the technical and tactical component of golf tasks.

Additionally, results of the present article confirm the presence of links among imagery function, content and characteristics. Indeed, in the first study, the three different research methods highlighted that expert golfers use content and characteristics of mental images according to the function of these images. These links are shown in Study 2 with the chi-square test processed among variables related to content (perspective and focus) and function, but also among variables dealing with characteristics (vividness, speed and colour) and function. Significant links have been observed between perspective and function, and between focus and function. This link between the content of mental images and their function confirms the relationship between these two constructs presented in Nordin and Cumming (2005) and Fournier et al.'s (2008) model. Similarly, significant links were observed between vividness and function, speed and function and colour and function. This link between characteristics and function was demonstrated in previous articles that highlighted in particular the link between speed and function (Calmels \& Fournier, 2001; Fournier et al., 2008; Jenny \& Hall, 2009). In contrast with the PETTLEP approach, (Holmes \& Collins, 2001) which recommends imagining in real time, that is to say to respect the temporal characteristics of the skill being imagined, the former articles have demonstrated that athletes voluntarily use various image speeds depending on the function of their images, as noted in the two studies with expert golfers. All these results tend to confirm the functional aspect of the use of imagery. lndeed, golfers adapt the content and the characteristics of their mental images to the functions that they attribute to these images.

\section{Influence of the situation}

Some applied models of imagery use (Fournier et al., 2008; Martin et al., 1999; Munroe et al., 2000) mention the importance of the situation in which the athlete is found when he/she uses mental imagery. Thus it was necessary to examine the influence of the situation on imagery use in these two studies in golf. Study 1 highlights links among function, content and characteristics and the situation in which the players are immersed. The players claim to use imagery for different reasons depending on the shot they played (shot type and difficulty), and on the environmental conditions. In addition, they adapt the content and the characteristics of mental images to the specificities of the situation. In Study 2, the 2 x 2 situations (task- vs. ego-involving situations and easy vs. difficult shots) that we tried to create do not seem to influence the function for which golfers used imagery.

Results of Study 2 regarding the influence of the situation must be interpreted with caution. A validity check confirmed that performance on the easy chips was significantly higher than performance on the difficult chips. Therefore two distinct levels of difficulty were effectively created. However, the manipulation of motivational situation might have not been efficient. Even in the task-involving situation, we observed that players compared their performance to the performance of the other golfers, and to their own performance on the previous shot. While we specified to the players of the task-involving situation group that the goal was to work on their short game (chipping), they reported that they paid attention to their performance, that they tried to improve their performance and to score higher than the other participants, because they were watching the others' performance when they were moving from one chip to the next. Therefore the importance attributed to performance in the task-involving situation appeared similar to that of the players in the egoinvolving situation. A link between motivational orientations and imagery use was demonstrated by Cumming, Hall, Harwood, and Gammage (2002) and Harwood, Cumming, and Hall (2003). Results from these studies led to the hypothesis that motivational situation influences imagery functions through motivational orientation. However, in the present study, it is not clear that the motivational situation was manipulated as planned. Therefore it was not possible to observe difference of imagery use that might have been produced by different motivational orientation induced by the situation.

In short, the link between situation and the function of mental images has not been confirmed. More research is needed to better understand the hypothetical link presented in various models (Fournier et al., 2008; Martin et al., 1999; Munroe et al., 2000).

\section{Content mainly used}

For expert golfers, images of the outcome from an internal perspective is the content most used in these two studies. In Study 1, all participants use images of the ball trajectory or roll from an 
internal perspective. Sometimes they use other image content (focused on process or with an external perspective) to adapt the image content to the situation and the function. In Study 2, although content differences are observed according to the image function, the images of the outcome from an internal perspective are most used out of all the observations. The effect of this content on performance is not the focus of this article. However, the prevalent and preferred use of internal perspective warrants examination in light of research investigating the effectiveness of imagery perspective. The numerous studies comparing the two perspectives (e.g., Hardy \& Callow, 1999; White \& Hardy, 1995) have highlighted the functional aspect of mental images. Indeed, the two perspectives are not used for the same functions and vary according to the situation, in particular, the task. For example, White and Hardy (1998) underlined that both perspectives fulfill respective functions that must be distinguished. External imagery allows for enhancing the speed of task execution while internal perspective enhances the precision of the move. Holmes and Collins (2001) have suggested directing research towards the adaptation of image perspective in function of the individual and the task at hand.

Regarding the focus of attention in imagery, images of the outcome are more prevalent than the other categories of focus (images of the process, images of process and outcome, no image). Indeed the most widely used focus in imagery experiences of the golfers is related to the ball trajectory or roll. Even if this article did not deal with the effect of focus of attention in imagery on performance, we observed that expert players in the two studies preferentially and voluntarily used images of the outcome. The focus also turned out to be related to the function of the images. Thus, in Study 2, golfers used more images of the process or images of both process and outcome when the function was to learn or to enhance the swing. These results regarding focus of attention in imagery can be seen through the lens of theories related to attentional strategies in sport. Numerous studies have examined the effectiveness of focus of attention in experts and novices (e.g., Beilock, Carr, \& Wierenga, 2002; Masters \& Maxwell, 2004; Wulf \& Prinz, 2001). However, few studies address the effectiveness of focus of attention in mental imagery. Only one study (Caliari, 2008) has demonstrated that, in their imagery, novice table tennis players focusing on the trajectory of the racket were more successful in forehand acquisition than players focusing, in their imagery, on the trajectory of the ball. The equivalence (or non equivalence) between foci of attention in mental imagery and foci of attention in real practice is a relevant avenue of research.

\section{Conclusion}

Results confirmed some of the recent findings in the literature. The next step is to investigate imagery use in other sports, at various levels of practice. Since this article mainly focused on visual imagery, it is also necessary to supplement the present investigation by examining the use of kinaesthetic and other modalities by expert golfers. The situation in which imagery is used appears to be a key element. Future studies should examine imagery use in various situations (e.g., in training and competition, in situations of failure or success). In addition to our knowledge of structural aspects, a better knowledge of functional links could certainly allow us to enhance the quality of sport psychology consultants' interventions. Focusing on the functions of imagery helps the sport psychology practitioner better understand athletes' use of imagery and conceive imagery-training programs adapted to particular athletes and to specific situations.

\section{Acknowledgments}

The authors wish to thank the elite golfers who participated in these studies. Both studies were undertaken with a research grant from the French Federation of Golf. Additional thanks to Laura Killian, Brice Lefèvre and Rémy Dinh-Phung for their comments on the manuscript. 


\section{References}

Ames, C. (1992). Achievement goals, motivational climate, and motivational processes. In G. Roberts (Ed.), Motivation in sport and exercise (pp. 161-176). Champaign, IL: Human Kinetics Publishers.

Beilock, S. L, Carr, T. H., \& Wierenga, S. A. (2002). Expertise, attention, and memory in sensorimotor skill execution: impact of nove) task constraints on dual-task performance and episodic memory. The Quarterly Journal of Experimental Psychology, 55, 1211-1240.

Caliari, P. (2008). Enhancing forehand acquisition in table tennis: the rote of mental practice. Journal of Applied Sport Psychology, 20, 88-96.

Calmels, C., D'Arripe-Longueville, F., Fournier, J. F., \& Soulard, A. (2003). Competitive strategies among elite female gymnasts: an exploration of the relative influence of psychological skills training and natural learning experiences. International Journal of Sport and Exercise Psychology, 1, 327-352.

Calmels, C., \& Fournier, J. F. (2001). Duration of physical and mental execution of gymnastics routines. The Sport Psychologist, 15, 142-150.

Cibois, P. (1993). Le PEM, pourcentage de l'écart maximum: un indice de liaison entre modalités d'un tableau de contingence. [The PEM, percentage from maximum deviation: an index of tie between modalities of a contingency table]. Bulletin of Sociological Methodology, 40, 43-63.

Cibois, P. (2009). Percentage of maximum deviation from independence (PEM) -comment on Lefèvre and Champely's "Analyse d'un tableau de contingence". Bulletin of Sociological Methodology, 103, 66-74.

Cumming, J., Clark, S. E.. Ste-Marie. D. M., McCullagh, P.. \& Hall, C. (2005). The functions of observational learning questionnaire (FOLQ). Psychology of Sport and Exercise, 6, 517-537.

Cumming, J., Hall. C., Harwood, C. G. \& Gammage, K. (2002). Motivational orientations and imagery use: a goal profiling analysis. Journal of Sports Sciences, 20, 127-136.

Driskell, J., Copper, C., \& Moran, A. (1994). Does mental practice enhance performance? A metaanalysis. Journal of Applied Psychology, 79, 481-492.

Ericsson, K. A., Krampe, R. T., \& Tesch-Rômer, C. (1993). The role of deliberate practice in the acquisition of expert performance. Psychological Review, 100, 363-406.

Fournier, J. F., Deremaux, S.. \& Bernier, M. (2008). Content, characteristics and function of mental images. Psychology of Sport and Exercise, 9, 734-748.

Fournier, J. F., LeCren, F., Monnier, E. (1994) Validation et adaptation en langue française du questionnaire de clarté de l'image du mouvement ! Validation and adaptation in French of the vividness of movement imagery questionnaire]. Paper presented at the international conference of the French Sport Psychology Society (SFPS), Poitiers, France.

Gregg, M., Hall, C., \& Nederhof, E. (2005). The imagery ability, imagery use and performance relationship. The Sport Psychologist, 19. 93-99.

Grimmer, J. F. (2004). Statbox (Version 6.4). Paris: Grimmer Soft. [Computer Software Paris] 
Hall, C. R., Mack, D. E., Paivio, A.. \& Hausenblas, H. A. (1998). Imagery use by athletes: development of the sport imagery questionnaire. International Journal of Sport Psychology, 29, 7389.

Hardy, L, \& Callow, N. (1999). Efficacy of external and internal visual imagery perspectives for the enhancement of performance on tasks in which form is important. Journal of Sport and Exercise Psychology. 21, 95-112.

Hardy. L. \& Jones. G. (1994). Current issues and future directions for performance-related research in sport psychology. Journal of Sports Sciences, 12, 61-92.

Hare, R., Evans, L, \& Callow, N. (2008). Imagery use during rehabilitation from injury: a case study of an elite athlete. The Sport Psychologist, 22, 405-422.

Harwood, C., Cumming. J.. \& Hall, C. R. (2003). Imagery use in elite youth sport participants: reinforcing the applied significance of achievement goal theory. Research Quarterly for Exercise and Sport; 74, 292-300.

Holmes, P. S., \& Collins, D. J. (2001). The PETFLEP approach to motor imagery: a functional equivalence mode! for sport psychologists. Journal of Applied Sport Psychology, 13, 60-83.

Isaac, A. R., Marks, D. F., \& Russell, D. G. (1986). An instrument for assessing imagery of movement: the vividness of movement imagery questionnaire. Journal of Mental Imagery, 10, 23 30.

Jeannerod, M. (2001). Neural simulation of action: a unifying mechanism for motor cognition. NeuroImage, 14, 5103-S109.

Jenny. 0., \& Hall, C. (2009). A quantitative analysis of athletes' voluntary use of slow motion, real cime, and fast motion images. Journal of Applied Sport Psychology, 21, 15-30.

Martin, K. A., Moritz, S. E., \& Hall, C. R. (1999). Imagery use in sport: a literature review and applied model. The Sport Psychologist, 13, 245-268.

Masters, R. S. W., \& Maxwell, J. P. (2004). Implicit motor learning, reinvestment and movement disruption: what you don't know won't huit you. In A. M. Williams, N. J. Hodges (Eds.), SkilI acquisition in sport: Research, theory and practice. London, UK: Routledge.

Morgan, D. L, \& Krueger, R. A. (1998). The focus group kit. Thousand Oaks, CA: Sage. Munroe, K. J., Giacobbi, P. R., Hall, C. R., \& Weinberg, R. (2000). The four Ws of imagery use: where, when, why and what. The Sport Psychologist, 14,119-137.

Murphy, S., Nordin, S. M., \& Cumming, J. (2008). Imagery in sport, exercise and dance. In T. Horn (Ed.), Advances in sport and exercise psychology (3rd ed.). (pp. 297-324) Champagne, IL: Human Kinetics.

Nichoils, J. G. (1989). The competitive ethos and democratic education. Cambridge, MA: Harvard University Press.

Nordin, S. M., \& Cumming, J. (2005). Professional dancers describe their imagery: where, when, what, why, and how. The Sport Psychologist, 19, 395-416.

Paivio, A. (1985). Cognitive and motivational functions of imagery in human performance. Canadian Journal of Applied Sport Sciences, 10. 22S-28S. 
Patton, M. Q (2002). Qualitative evaluation and research methods (3rd ed.). Thousand Oaks, CA: Sage.

Pearson Longman. (2009). Situation - definition from Longman English dictionary. Retrieved 26.10.09, from. http://www.ldoceonline.com/dictionary/situation.

Short, S. E., Bruggeman, J. M., Engel, S. G., Marback, T. L, Wang, L J., Willadsen, A., et al. (2002). The effect of imagery function and imagery direction on selfefficacy and performance on a golf-putting task. The Sport Psychologist, 16, 48-67.

Short, S. E., Monsma, E. V., \& Short, M. W (2004). Is what you see really what you get? Athletes' perceptions of imagery's functions. The Sport Psychologist, 18, 341-349.

Sparkes, A. C. (1998). Validity in qualitative inquiry and the problem of criteria:

implications for sport psychology. The Sport Psychologist, 12, 363-386. Thomas, J. R., \& Nelson, J. K. (1996). Research methods in physical activity. Champaign. IL: Human Kinetics.

Trudel, P., Haughian. L, \& Gilbert, W. (1996). L'utilisation de la technique du rappel stimulé pour mieux comprendre le processus d'intervention de l'entraîneur en sport. [Use of the stimulated recall technique to better understand the intervention process in sport coachingj. Revue des Sciences de l'Education, 22, 503-522.

Von Cranach, M., \& Narré, R. (1982). The analysis of action: Recent theoretical and empirical advances. Cambridge: Cambridge University Press.

White, A., \& Hardy, L (1995). Use of different imagery perspectives on the learning and the performance of different motor skills. British Journal of Psychology, 86, 169-180.

White, A., \& Hardy, L (1998). An in-depth analysis of the uses of imagery by highlevel slalom canoeists and artistic gymnasts. The Sport Psychologist, 12, 387-403.

Wulf, G., \& Prinz, W. (2001). Directing attention to movement effects enhances learning: a review. Psychonomic Bulletin \& Review, 8, 648-660. 
Fig.1. Categories of situation, function, content and characteristics of mental images used by expert golfers.

\section{SITUATION}

Type of shot (e.g., drive, chip, putt);

Environmental conditions (e.g., lie of the ball, obstacles, meteorological conditions);

Step of the shot routine (e.g., during the practice swing, at address);

Psychological state (e.g., confidence state, anxiety state);

Moment of a training session (before, during, alter a training session);

Moment of a competition (e.g., the day before a competition, just before teeing off);

Period of training (e.g., competition, tapering).

\section{FUNCTION}

To focus (e.g., to focus on relevant information, to avoid thinking about the technical aspects of the swing);

To learn or perfect the swing (e.g., to check the amplitude of the backswing, to find the right rhythm);

To prepare strategic and tactical aspects (e.g., to choose the club, to choose the shot, to plan a strategy on a round);

To manage a psychological state (e.g., to enhance confidence, to manage arousal);

To evaluate a shot

\begin{tabular}{|c|c|c|}
\hline \multicolumn{2}{|c|}{ CONTENT } & CHARACTERISTICS \\
\hline $\begin{array}{l}\text { FOCUS } \\
\text { The results of the } \\
\text { action (e.g., the fine of } \\
\text { the putt, the different } \\
\text { possible trajectories of } \\
\text { the ball, the target, the } \\
\text { hole); } \\
\text { The swing (the club } \\
\text { motion, a part of or the } \\
\text { whole body movement). }\end{array}$ & $\begin{array}{l}\text { PERSPECTIVE } \\
\text { With an internal } \\
\text { perspective; } \\
\text { With externat perspective. }\end{array}$ & $\begin{array}{l}\text { Speed (e.g., in real time, in slow motion or } \\
\text { fast forward); } \\
\text { Colour (e.g., in black and white, in colour); } \\
\text { Vividness (e.g., blurry, vivid images). }\end{array}$ \\
\hline
\end{tabular}


Table 1 : Percentages of content (perspectives and foci) used for each function.

\begin{tabular}{|c|c|c|c|c|c|c|c|}
\hline \multirow[b]{2}{*}{ Function } & \multicolumn{3}{|l|}{ Perspectives } & \multicolumn{4}{|c|}{ Foci of attention } \\
\hline & $\begin{array}{l}\text { External } \\
\text { perspective }\end{array}$ & \begin{tabular}{|l|} 
Internal \\
perspective
\end{tabular} & $\begin{array}{l}\text { Internal } \\
\text { and } \\
\text { external } \\
\text { perspective }\end{array}$ & $\begin{array}{l}\text { Images } \\
\text { of the } \\
\text { process }\end{array}$ & $\begin{array}{l}\text { Images } \\
\text { of the } \\
\text { outcome }\end{array}$ & $\begin{array}{l}\text { Images } \\
\text { of } \\
\text { process } \\
\text { and } \\
\text { outcome }\end{array}$ & $\begin{array}{l}\text { No } \\
\text { image }\end{array}$ \\
\hline $\begin{array}{l}\text { To learn } \\
\text { and } \\
\text { perfect the } \\
\text { swing }\end{array}$ & 22 & 62 & 16 & 24 & 45 & 28 & 4 \\
\hline To focus & 11 & 75 & 14 & 7 & 69 & 24 & 0 \\
\hline $\begin{array}{l}\text { To } \\
\text { perform }\end{array}$ & 39 & 44 & 17 & 19 & 65 & 16 & 0 \\
\hline $\begin{array}{l}\text { To gain } \\
\text { confidence }\end{array}$ & 23 & 70 & 7 & 5 & 37 & 59 & 0 \\
\hline $\begin{array}{l}\text { To } \\
\text { manage } \\
\text { stress and } \\
\text { arousal }\end{array}$ & 64 & 27 & 9 & 9 & 41 & 27 & 23 \\
\hline $\begin{array}{l}\text { To get } \\
\text { motivated }\end{array}$ & 33 & 50 & 17 & 25 & 63 & 12 & 0 \\
\hline $\begin{array}{l}\text { Average } \\
\text { for all } \\
\text { shots }\end{array}$ & 32 & 55 & 13 & 15 & 53 & 28 & 4 \\
\hline
\end{tabular}


Table 2 : Percentages of characteristics (vividness, speed and colour) used for each function.

\begin{tabular}{|c|c|c|c|c|c|c|c|c|}
\hline \multirow[b]{2}{*}{ Function } & \multicolumn{3}{|c|}{ Vividness } & \multicolumn{3}{|l|}{ Speed } & \multicolumn{2}{|l|}{ Colour } \\
\hline & Vivid & Blurry & $\begin{array}{l}\text { Very } \\
\text { blurry }\end{array}$ & Slower & Real & Faster & $\begin{array}{l}\text { In } \\
\text { colour }\end{array}$ & $\begin{array}{l}\text { In black } \\
\text { and } \\
\text { white }\end{array}$ \\
\hline $\begin{array}{l}\text { To learn } \\
\text { and } \\
\text { perfect } \\
\text { the swing }\end{array}$ & 56 & 34 & 10 & 22 & 58 & 19 & 88 & 12 \\
\hline To focus & 61 & 35 & 4 & 37 & 52 & 11 & 98 & 2 \\
\hline $\begin{array}{l}\text { To } \\
\text { perform }\end{array}$ & 74 & 21 & 5 & 22 & 73 & 5 & 91 & 9 \\
\hline $\begin{array}{l}\text { To gain } \\
\text { confidence }\end{array}$ & 67 & 30 & 3 & 7 & 88 & 5 & 100 & $\mathbf{0}$ \\
\hline $\begin{array}{l}\text { To } \\
\text { manage } \\
\text { stress and } \\
\text { arousal }\end{array}$ & 35 & 39 & 26 & 26 & 63 & 11 & 73 & 27 \\
\hline $\begin{array}{l}\text { To get } \\
\text { motivated }\end{array}$ & 88 & 12 & $\mathbf{0}$ & 12 & 38 & 50 & 100 & 0 \\
\hline $\begin{array}{l}\text { Average } \\
\text { for all } \\
\text { shots }\end{array}$ & 64 & 28 & 8 & 21 & 62 & 17 & 92 & 8 \\
\hline
\end{tabular}

